surgical, medical, and obstetrical services" to the community; he rendered these in an efficient, kindly way. There is no doubt that he was a hard worker; I well remember being advised-when applying for the post-not to inquire which my half day would be! It was a busy, enjoyable 12 months and I indeed gained valuable experience. I am sure the trainees of the present time receive an equally sound practical education from their attachment to a group practice; I wonder how procedures and attitudes adopted now compare with those of 50 years ago.

It will be readily understood why the reference to the "Crichton Royal" (p 439) is of special interest when I mention that my fatherin-law, Dr C C Easterbrook, was superintendent of it from 1908 to 1937 . Three years after he retired he published an extensive book entitled The Chronicle of Crichton Royal, in which he gave a detailed history of this famous mental hospital. It was founded in 1839 through the kind generosity of $\mathrm{Dr}$ and Mrs James Crichton; their original plan to build a university at Dumfries was soon abandoned. Having been acquainted-over a long period -with the policies of progress which have been pursued in the institution (not as a patient, I hasten to add), I feel I am able to commend the exceptional facilities which exist there. A few good reasons why the NHS works well in Dumfries and Galloway are listed at the end of the article; I venture to stress one in particular - "the legacy of a large and beautiful psychiatric hospital."

Edinburgh EH4 3DP

GLYN LACKIE

\section{The sick doctor}

SIR,-It is difficult to see just what "the profession as a whole" can do for the sick doctor that is of practical value. Nevertheless, where personal or social conflict leaves an unsatisfactory environment some corrective action may be helpful.

The General Medical Council through its new Health Committee can now solve the problem of the doctor who is "clearly incapable of carrying out his duties." However, the problem of the doctor who drinks habitually is seldom clearcut. $\mathrm{He}$ is often able to function at a level where it is very difficult to prove that his medical reasoning is wrong because of alcoholism. Where a doctor is isolated from medical colleagues and on constant call alcohol abuse is prone to develop. This isolation can be remedied to some extent by regularreturning-locum appointments and early retirement for single-handed isolated practitioners.

Job satisfaction is of prime importance in maintaining a sober, rational enthusiasm in any work. Such enthusiasm cannot be maintained 24 hours a day, seven days a week, for very long. In isolated rural practices it is obviously not the rush of less than five-minute appointments that is demoralising but rather the constant awareness that there is no time, day or night, that cannot be interrupted by a call. There is no deputising service and no partner to take over. Under such circumstances neither inducement payments nor supplementary practice allowances substitute or make up for the lack of job satisfaction. The problem can be remedied, however, by a regular scheduled locum relief doctor. Such a system was successfully tried on our island and in the Orkneys for a time.
A second practical measure might be an early retirement for isolated single-handed practitioners, say between 55 and 60 . This would be a major step toward providing a source of well-trained, experienced practitioners who could fill the locum appointments for isolated practices.

THEODORE I JONES

Salen, Isle of Mull

\section{Generic prescribing}

SIR,-Dr Ronald Law, in his letter (16 August, p 520), is considering overstamping his FP10 NHS prescription forms with the words "The generic equivalent may be supplied."

Although I agree with the economic advantages of non-proprietary prescribing, there are instances where this may be dangerous. For example, where drugs are made by several companies there may be significant differences in the bioavailability of the active ingredients. A disregard of this factor may lead to treatment failure or to toxicity. ${ }^{1}$ This is more likely to be the case where a prescription originates in hospital, as with anticoagulants, cardiac glycosides, and antiepileptics. Here the general practitioner is less likely to be familiar with this particular risk, and he may by adopting Dr Law's idea inadvertently commute a prescription to the non-proprietary equivalent when repeating a prescription in his surgery. The consistent prescribing of a proprietary name for some drugs is therefore essential.

Incidentally, I wonder if I could point out the now popular catachresis of the word generic, where often it is used to mean nonproprietary. Generic means "belonging to a genus or class; applied to a large group or class of objects" (see Oxford English Dictionary and Laurence $^{2}$ ). By way of illustration, Mogadon is a proprietary name, nitrazepam a nonproprietary name; but benzodiazepine is the generic name.

If Dr Law does overstamp his FP10s, I suggest that he uses the formulation: "An equivalent non-proprietary preparation may/ may not be dispensed," thereby affording the option necessary to avoid the above hazard.

Northampton NN3 1BA

Michael Jolles

1 Lant A. Medicine, Series 3 (1978) issue 2, pages 99-112. burgh: Churchill Livingstone, 1973:5.1.

\section{The hospital practitioner grade}

Sir,-Dr D C Banks (9 August, p 458) obviously does not understand the hospital practitioner grade. It is a grade which was tailor made for principals in general practice who have a special interest and suitable experience enabling them to work in that specialty under consultant supervision for a maximum of five sessions a week. The terms and conditions of service were skilfully negotiated and the level of remuneration recognises not only the nature of the work being done but also the continuing practice expenses. It does not replace the medical assistant grade.

The fears which I expressed at the ARM were that if this grade is opened up to "other suitably qualified doctors" it would be filled by doctors with domestic commitments despite the fact that it would be an unsuitable grade for most of these doctors, who wish to continue their training and eventually undertake full clinical responsibility for their patients.

As the numbers of female graduates of our medical schools increase so the numbers of doctors with domestic commitments will increase. Many of these doctors will wish to become consultants. Their interests would be best served by creating more part-time posts in the training grades and not by creating a non-training grade at subconsultant level from which there would be little prospect of promotion.

G S MCCUNE

Milngavie, Glasgow

\section{"Batch" or "on-line" for child health}

SIR,-I have followed closely the discussions on the implementation of the standard child health computing system (28 June, p 1621; 5 July, p 90; 12 July, p 151; 26 July, p 312; 16 August, p 522), and I have noted with concern the apparent continuing disagreement between the BMA and the Child Health Computing Committee (CHCC).

It would seem to me that this would best be resolved by utilising the software format which has been devised by the CHCC in conjunction with an alternative hardware system with small peripheral units, in order that the advantages of modern computing technology can be combined with the committee's recommendations concerning the type of programme which it would be desirable to implement nationally. I must say that I am inclined to agree with the representatives of the BMA when they say that the committee's present proposals in relation to batch processing and large, main-frame computers are out of date; I feel that we should be taking advantage of microcomputing methods, as we are in this area at the present time in relation to other aspects of computing, and I feel that the best way to do this would be to combine the two elements in the competing proposals as I have suggested above.

I should like to see this done in two trial areas and it should be assessed and monitored by a small group of general practitioners and community physicians, none of whom is connected in any way with the Child Health Computing Committee or the BMA's Central Ethical Committee. The conclusions of this group, following the trials referred to, should then form the basis of a child health computing system to be run on microcomputers.

I trust that the chairman of the Child Health Computing Committee, with whom I have discussed this proposal already, will in turn discuss it with BMA representatives to see whether some agreement cannot be reached along the lines which I have suggested.

Paul J Heath

Barnsley Area Health Authority,
Barnsley, S Yorks S75 2PY

\section{No monopoly of success}

SIR,-Mr L P Fielding and his colleagues (9 August, p 411) find that some surgeons are better than others at fashioning large-bowel anastomoses-no great surprise perhaps. But why are they surprised to find that the more (and less) successful surgeons work in district as well as teaching hospitals ?

J C ANGELL

Ashford Hospital,
Ashford, Middx 